\title{
MEASUREMENTS OF DISTRIBUTION COEFFICIENTS AND LIPOPHILICITY VALUES FOR OLEANOLIC ACID AND BETULINIC ACID EXTRACTED FROM INDIGENOUS PLANTS BY HOLLOW FIBRE SUPPORTED LIQUID MEMBRANE
}

\author{
Christianah A. Elusiyan ${ }^{1}$, Titus A.M. Msagati ${ }^{2 *}$, Francis O. Shode ${ }^{3}$ and Bhekie B. Mamba ${ }^{2}$ \\ ${ }^{1}$ Drug Research and Production Unit, Obafemi Awolowo University, Ile-Ife, Nigeria \\ ${ }^{2}$ Department of Chemical Technology, Faculty of Science, University of Johannesburg, \\ Doornfontein Campus, P. O. Box 17001, Johannesburg 2028, Republic of South Africa \\ ${ }^{3}$ School of Chemistry, University of KwaZulu-Natal, Private Bag X54001 Westville Campus, \\ Durban 4000, Republic of South Africa
}

(Received March 18, 2010; revised May 1, 2011)

\begin{abstract}
Hollow fibre supported liquid membrane (HFSLM) has been applied in the measurements of distribution constants, $\mathrm{K}_{\mathrm{D}}$ and lipophilicity (log P) values for the isomeric triterpenic acids, betulinic acid (BA) and oleanolic acid $(\mathrm{OA})$ isolated from indigenous plants. The results have shown that $\mathrm{BA}$ had an optimum $\mathrm{pH}$ of 3.5 while the optimum sample $\mathrm{pH}$ for $\mathrm{OA}$ was ranging from 0.5 to 2.5 . The $\log \mathrm{P}$ values obtained for $\mathrm{BA}$ and $\mathrm{OA}$ were 6.61 and 6.12 , respectively. The $\mathrm{K}_{\mathrm{D}}$ value obtained for BA was 0.29 while that for OA 0.16 . The method has advantages of simplicity, use of minimal organic solvents and the ability to selectively extract only one isomer $(\mathrm{OA})$ in the mixture with BA by optimizing $\mathrm{pH}$ conditions.
\end{abstract}

KEY WORDS: Betulinic acid, Oleanolic acid, Hollow fibre supported liquid membrane, Distribution coefficient, Lipophilicity

\section{INTRODUCTION}

Betulinic acid (BA) and oleanolic acid (OA) are isomeric triterpenoid compounds with medicinal properties that have been isolated from many indigenous plants species. Betulinic acid for example, has been isolated from Quisqualis fructus (Fam. Combretaceae), Coussarea paniculata (Fam. Rubiaceae), Argentinean legume Caesalpinia paraguariensis (Fam. Fabaceae), Vitex negundo (Fam. Verbenaceae), Ilex macropoda (Fam. Aquifoliaceae), Anemone raddeana (Fam. Ranunculaceae), and Doliocarpus schottianus (Fam. Dilleniaceae), to mention a few [1]. Oleanolic acid has been isolated from Rosa woodsii (Fam. Rosaceae), Prosopis glandulosa (Fam, Fabaceae), Phoradendron juniperium (Fam. Viscaceae), Syzygium claviflorum (Fam. Myrtaceae), Hyptis captata (Fam. Labiatae), and Temstromia gymnanthera (Fam. Theaceae), amongst others [2]. Betulinic acid has been reported to selectively induce apoptosis in tumor cells through mitochondrial permeability transition pathway [3-5]. Oleanolic acid on the other hand has been used for treatment of lung cancer and has also antiinflammatory, anti-hyperlipidemic properties and antitumor effects $[6,7]$. Both BA and OA are also known to have anti-HIV-1 properties $[8,9]$.

Due to the medicinal values of BA and OA, it is imperative that the bioactivity properties for these compounds be determined using simple and reliable methods. The bioactivity of medicinal compounds can be determined by their lipophilicity values as well as the distribution coefficient $\left(\mathrm{K}_{\mathrm{D}}\right)$. Knowledge of the relationships between affinity to lipids and biological (anesthetic) activity of chemical substances was firstly reported by Overton and then by Meyer and Baum [10-12]. It is therefore important to develop simple and rapid procedures for determining lipophilicity parameters and $K_{D}$ values for bioactive compounds with very small samples.

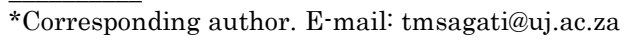


Traditionally, tube method has been predominantly used for the evaluation of lipophilicity values [13]. This method involves mixing a known amount of solute in a known volume of octanol and water, followed by measuring the distribution of the solute in each solvent using UV/Vis spectroscopy or other methods [14]. The method has advantages of high selectivity, broad range of solutes (neutral and charged compounds applicable) and also the fact that the chemical structure does not have to be known beforehand. The limitation of the method is realized from the fact that the method is time consuming.

In this work, we report the use of hollow fibre supported liquid membrane (HFSLM) technique to determine the $\log \mathrm{P}$ values of $\mathrm{BA}$ and $\mathrm{OA}$ in addition to its role as extraction and separation means for the two isomers. Reversed phase high performance liquid chromatography (RPHPLC) with UV-DAD detection as well as HPLC coupled to a mass spectrometer was used for separation and detection of the extracts.

HFSLM is a non-porous membrane technique which has been widely used for selective preconcentration of both organic and inorganic extracts [15-17]. With the HFSLM technique, the analyte is contained in an aqueous sample solution and for it to be extracted it should be in its neutral form. The organic solvent is impregnated in the pores of the hollow fibre which separates the sample solution from stripping (acceptor) solution contained in the lumen of the hollow fibre [18]. The concentration gradient develops between sample solution and acceptor phase which allows the dissolved analytes to be transported through the organic phase (impregnated in the pores of the hollow fibre) to acceptor solution (in the lumen of the hollow fibre) [19].

HFSLM was chosen for the study because of its numerous advantages. HFSLM techniques incorporate low pore sized hollow fibre and therefore more efficient in its selectivity. It involves simple extraction set up, easy sample preparation with less preparation time unlike most sample preparation methods. Moreover, there is no direct contact between the sample solution and acceptor phase and therefore ion transfer occurs through the organic solvent filled hollow fibre pores. The extract is very clean as contaminants do not cross the hydrophobic membrane and is highly selective when parameters affecting extraction are well optimized. HFSLM also lowers the limit of detection because of the high pre-concentration factors obtained which result into enhanced signals [20].

In this study, authentic samples of BA and OA were isolated from Tectonia grandis, family Verbenaceae (stem bark) and Syzygium aromaticum, family Myrtaceae (cloves), respectively. BA/OA mixture was isolated as a co-mixture from the leaves of Meleleuca bracteata, family Myrtaceae, 'Johannesburg Gold' (South African Tea Tree). The structures of BA and OA are shown in Figure 1.

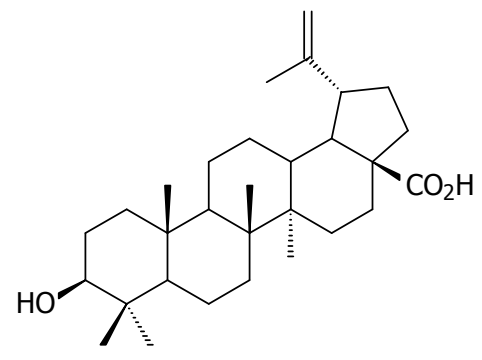

(a)

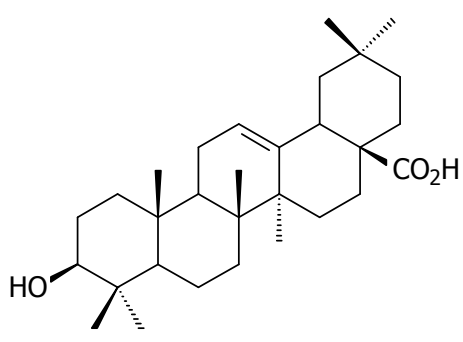

(b)

Figure 1. (a) Betulinic acid (BA). (b) Oleanolic acid (OA). 


\section{EXPERIMENTAL}

\section{Instrumentation and apparatus: HPLC-UV-DAD and HPLC-ESI-MS experiments}

Agilent 1200 series HPLC (Wilmington, DE, USA) equipped with auto sampler, degasser, and a UV-DAD detector as well as a C18, XDB column, $4.6 \mathrm{~mm}$ x $50 \mathrm{~mm}$ x $1.8 \mu \mathrm{m}$ ) were used. The detection wavelength of $254 \mathrm{~nm}$ was used for the compounds. The mobile phase was $75 \%$ methanol and $25 \%$ water. Injection volume was $5 \mu \mathrm{L}$ at a flow rate of $0.3 \mathrm{~mL} / \mathrm{min}$.

The HPLC-ESI-MS system used for this work consisted of an Agilent Hewlett-Packard 1100 Series HPLC connected to Agilent 1100 Series LC/MSD Trap mass spectrometer (Wilmington, DE, USA). The quadrupole temperature of the MS was $120{ }^{\circ} \mathrm{C}$ and the mass chromatograms were acquired in the selected ion mode (SIM) for the negative mode of both OA and BA $(\mathrm{m} / \mathrm{z}=$ 455). The temperature of the drying gas, $\mathrm{N}_{2}$, was $300{ }^{\circ} \mathrm{C}$ and the flow rate of the nebulizing gas, $\mathrm{N}_{2}$, was $40 \mathrm{~mL} / \mathrm{min}$, being maintained at $80 \mathrm{psi}$.

An analytical Mettler AE240 balance was used for all measured weights. Magnetic stirrer bar and stirrer plate (Bibby HB 502) were used during sample extraction. The polypropylene hollow fibre tubing ( $50 \mu \mathrm{m}$ wall thickness, $280 \mu \mathrm{m}$ inner diameter and $0.1 \mu \mathrm{m}$ pore size) was used with needle of BD micro-fine syringe (needle of $0.3 \mathrm{~mm}$ outer diameter, a length of $8 \mathrm{~cm}$ and $100 \mu \mathrm{L}$ holing volume (SGE, Australia). $\mathrm{pH}$ meter -430 Corning was used for all $\mathrm{pH}$ measurements.

\section{Chemicals, reagents and materials}

Di-n-hexyl ether (DHE), isooctane, octanol and undecane were purchased from Sigma Aldrich (St. Louis, MO, USA), while sodium hydroxide (analytical grade) and hydrochloric acid (32\%) were obtained from Merck (Darmstadt, Germany). The organic solvents used as mobile phase during separation (methanol and acetonitrile) were of HPLC grade and were purchased from BDH (Poole, England). Reagent water used was purified using a Mill- $\mathrm{Q}^{\circledR}$ reagent water system (Millipore, Molsheim, France).

Buffer solutions of different $\mathrm{pH}$ values were prepared according to the standard procedures [22]. The Q3/2 Accurel polypropylene hollow fibre membranes $(200 \mu \mathrm{m}$ wall-thickness, 600 $\mu \mathrm{m}$ inner diameter, $0.2 \mu \mathrm{m}$ pore size) were obtained from Membrana GmbH (Wuppertal, Germany). A 500- $\mu \mathrm{L}$ HPLC syringe was used for filling the acceptor solution into the lumen of the hollow fibre for extraction as well as flushing out the acceptor after extraction into a $100 \mu \mathrm{L}$ conical glass microinsert fitting in standard 2-mL autosampler vials.

Plant materials

The leaves of Melaleuca bracteata F. Muell. 'Revolution Gold' or Melaleuca bracteata F. Muell. 'Johannesburg Gold' (Myrtaceae family) (common names: Johannesburg gold or South African tea tree) were collected from the Nursery of the Ethekweni Municipality Parks and Gardens, KwaZulu-Natal, Durban and authenticated by Prof. H. Baijnath, School of Biological \& Conservation Sciences, University of KwaZulu-Natal (UKZN), Durban Centre, South Africa. A voucher number, Glow OO1 was given to a sample of the leaves and deposited at the Ward Herbarium, UKZN, School of Biological \& Conservation Sciences. Syzygium aromaticum (cloves) were purchased from a local spice shop in Durban, South Africa. Tectonia grandis stem barks were collected along Ondo road, Ile Ife, Nigeria. The plant was identified by Mr. Yakubu of the herbarium section of the Faculty of Pharmacy, Obafemi Awolowo University (OAU), Ile Ife. 
Analytical procedures

Preparation of plant materials and Isolation of $O A$ and $B A$

Oleanolic acid. Syzygium aromaticum (cloves) (whole, $100 \mathrm{~g}$ ) were defatted using hexane followed by extraction with dichloromethane and ethyl acetate, successively. The oily residues obtained after the removal of organic solvents under reduced pressure were combined and triturated/pulverized with hexane to give a precipitate of crude OA. Column chromatography of the crude OA over silica gel 60 (230-400 mesh ASTM) using solvent system hexane-ethyl acetate (7:3) gave pure OA with spectral data identical with the literature values [21].

Betulinic acid. T. grandis stem barks were oven-dried $\left(60^{\circ} \mathrm{C}\right)$ for 2 days and powdered using a laboratory mill. The powdered stem barks $(860 \mathrm{~g})$ were macerated in ethyl acetate $(3 \mathrm{~L})$ for $24 \mathrm{~h}$, filtered and evaporated to a minimum volume in vacuo using a rotary evaporator. The residue was allowed to dry at room temperature to give crude BA. Upon recrystallisation from methanol, pure BA (2.64 g) was obtained.

Betulinic acid/oleanolic acid mixture. Revolution gold (dried leaves, 342 g) were exhaustively extracted with ethyl acetate. The extract was evaporated to complete dryness in vacuo using a rotary evaporator, to yield a crude extract $(34 \mathrm{~g})$. A portion of the solid crude extract $(29 \mathrm{~g})$ obtained was purified by column chromatography over silica gel 60 (230-400 mesh ASTM) with hexane-ethyl acetate (7:3) solvent system as the mobile phase. The obtained BA/OA solid was charcoaled to give colourless mixture of BA/OA.

Preparation of analyte sample. The samples of pure BA and OA and the mixture of the two acids were extracted from Tectona grandis, Syzygium aromaticum, and Melaleuca bracteata 'Revolution gold', respectively. BA and OA mixture $(0.1 \mathrm{~g})$ was placed in a glass vial and dissolved with methanol $(20 \mathrm{~mL})$. From this solution, $2 \mathrm{~mL}$ were transferred into $250 \mathrm{~mL}$ volumetric flasks and made up to volume with deionized water. The $\mathrm{pH}$ meter was calibrated using $\mathrm{pH} 4$ and $\mathrm{pH} 7$ solutions. From the analyte sample, $10 \mathrm{~mL}$ aliquots were transferred into vials and adjusted to $\mathrm{pH}$ ranging from 0.5 to 4.5 for optimization experiments.

Preparation of standard solution. Standard solutions were prepared from pure BA and OA by dissolving $0.02 \mathrm{~g}$ of each compound in $10 \mathrm{~mL}$ methanol followed by transferring $3 \mathrm{~mL}$ of resulting solution into $100 \mathrm{~mL}$ volumetric flask which was further diluted to give series of standard solutions. This was done to identify the acids according to how they elute from the HPLC column.

Preparation of HFSLM and analyte sample extraction and separation. The hollow fibre tube used in this work was Q3/2 Accurel polypropylene hollow fibre membrane $(200 \mu \mathrm{m}$ wall thickness, $600 \mu \mathrm{m}$ inner diameter, $0.2 \mu \mathrm{m}$ pore size) obtained from Membrana $\mathrm{GmbH}$ (Wuppertal, Germany). The hollow fibres were cut into $4 \mathrm{~cm}$ length pieces, soaked in acetone for 20 minutes for cleaning and one end of each piece was sealed. The lumen of the hollow fibre was filled completely with $\mathrm{pH} 8$ buffer solution (acceptor aqueous phase) using a needle of BD micro-fine syringe, $100 \mathrm{~mL}$. The syringe was attached to the open end of the fibre and the outer membrane of the hollow fibre was impregnated with di-n-hexyl ether (organic phase) for about 5 seconds. The excess organic solvent was then washed with deionized water [19].

The HFSLM was immersed in $\mathrm{pH} 0.5$ analyte sample in a vial with a magnetic stirrer bar on a stirrer plate, and extracted with constant stirring for a period of 30 minutes. Thereafter the accepter solution was flushed into a modified HPLC sample vial consisting of well sized micro pipette tip and the extract was injected into the HPLC. The resulting solution from extraction 
was further extracted for $30 \mathrm{~min}$ (each sample extracted twice at the same $\mathrm{pH}$ ) and the $\mathrm{pH}$ was increased to 3.5 and the same extraction procedure was followed to exhaustively extract BA component.

Determination of $K_{D}$ and lipophilicity $(\log P)$ experiments. For the determination of distribution coefficient and lipophilicity values for a sample solution with the same concentration levels and at optimal conditions (acceptor $\mathrm{pH} 8.0$, room temperature) were extracted after having been enriched at different length of times. The enrichment time in this case was varied from 5 to 90 min. The amount extracted and the flux rate were then determined which made it possible to evaluate both $\mathrm{K}_{\mathrm{D}}$ and $\log \mathrm{P}$ values for $\mathrm{BA}$ and $\mathrm{OA}$.

\section{RESULTS AND DISCUSSION}

\section{The choice of organic solvent}

Selection of an organic solvent for HFSLM extraction is very crucial and many considerations had to be taken into account to get a suitable solvent. Some of these considerations include that the solvent has to have low volatility to prevent loss due to evaporation during the extraction process, low water solubility and also the analytes must be soluble in it. In this work, four different organic solvents were evaluated for their suitability. The solvents evaluated included DHE, n-undecane, DHE + n-undecane (1:1), toluene and isooctane. Of the various liquid membranes tested, DHE was found to be the best liquid for the selective extraction of OA and BA.

Sample pH optimization for the selective HFSLM extraction and separation of the isomers (BA and $O A$ )

It has been reported that a reduction in sample $\mathrm{pH}$ for polar weakly acidic compounds improves their extraction efficiency $[23,24]$. The influence of sample $\mathrm{pH}$ on the selective extraction of $\mathrm{OA}$ and BA was investigated in the $\mathrm{pH}$ range of 0.5 to 4.5 . Figures 2 and 3 show the results of sample $\mathrm{pH}$ optimization for all the compounds analyzed. The results show that the sample $\mathrm{pH}$ made it possible to selectively extract one isomer (OA) while leaving the other isomer (BA) in the sample solution. At a very low $\mathrm{pH}$ of $0.5-2.5 \mathrm{OA}$ became more extractable than BA and therefore, this made it possible to extract $\mathrm{OA}$ exhaustively (at lower $\mathrm{pH}$ of 0.5 ) and then obtain a higher percentage of pure BA component (at slightly higher $\mathrm{pH}$ of 3.5).

From Figures 2 and 3, it can be observed that as the sample $\mathrm{pH}$ was increased, the peak areas increased to an optimum value. The peak area is proportional to the concentration of the analyte therefore, at $\mathrm{pH} 2.5$ the greatest concentration of the compound OA was extracted and this was the optimum sample $\mathrm{pH}$ and the greatest concentration of compound $\mathrm{BA}$ was at $\mathrm{pH} 3.5$.

Separation and detection of the extracts using HPLC-UV-DAD and LC-ESI-SIM-MS

Extracts from HFSLM were analyzed using both HPLC-UV-DAD and LC-ESI-SIM-MS. Figure 3 shows the chromatograms of the separated isomers at the optimal sample $\mathrm{pH}$ for the two isomers, OA and BA. At $\mathrm{pH} 0.5$ it was possible to selectively extract only OA. When the $\mathrm{pH}$ was increased, it was observed that, both OA and BA were extracted. With this method, it is possible to extract exhaustively $\mathrm{OA}$ at $\mathrm{pH} 0.5$ and then increase $\mathrm{pH}$ of the remaining solution to between 2.5 and 3.5 and extract BA. The results prove the high selectivity of the HFSLM technique which removes the necessity of the HPLC separation step as far as these isomers is concerned. 


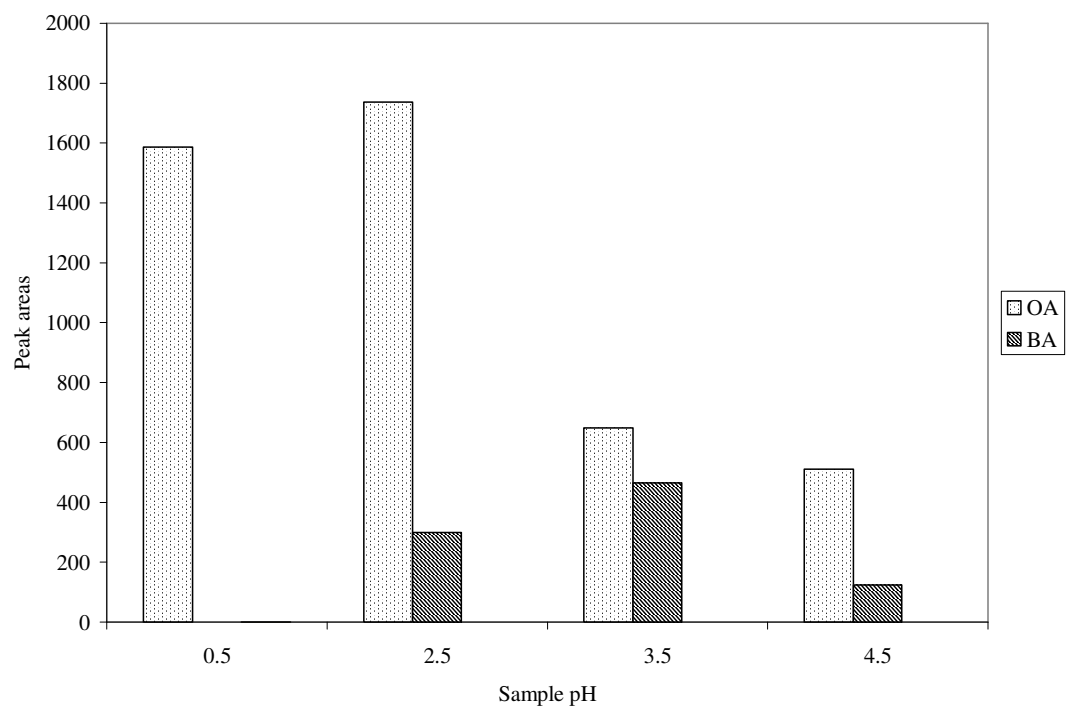

Figure 2. The effect of increasing sample $\mathrm{pH}$ for $\mathrm{OA}$ and $\mathrm{BA}$.

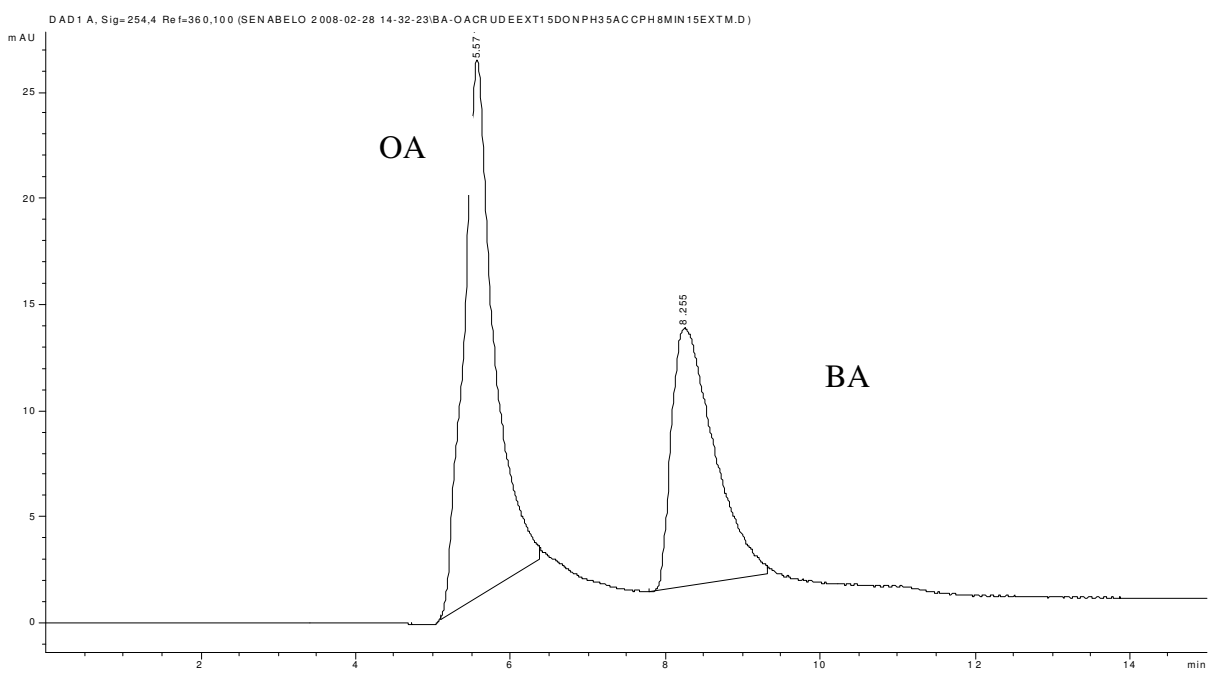

Figure 3. HPLC-UV-DAD chromatograms for sample from HFSLM extraction of crude mixture containing both $\mathrm{OA}$ and $\mathrm{BA}$ at $\mathrm{pH} 3.5$.

The extraction and separation of the two isomers were further verified using LC-ESI MS (negative mode). With this method, it was possible to monitor a number of ions that were observed which included the deprotonated molecular ion $(\mathrm{m} / \mathrm{z} 455)$. However, it is assumed that the other ions (apart from the deprotonated molecular ions) were formed in the MS and not during the HFSLM extraction, since in the HPLC chromatograms only two peaks were identified. For this reason, the deprotonated ion was the only ion used for the quantification process in the determination of $K_{D}$ and $\log P$ values for the HFSLM extracts.

Bull. Chem. Soc. Ethiop. 2011, 25(3) 
The identification of ESI-SIM-MS ion masses from both OA and BA is given in Table 1. All the fragments that were observed can be best described using retro-Diels-Alder mechanism.

Table 1.Identity of LC-ESI-SIM-MS fragments.

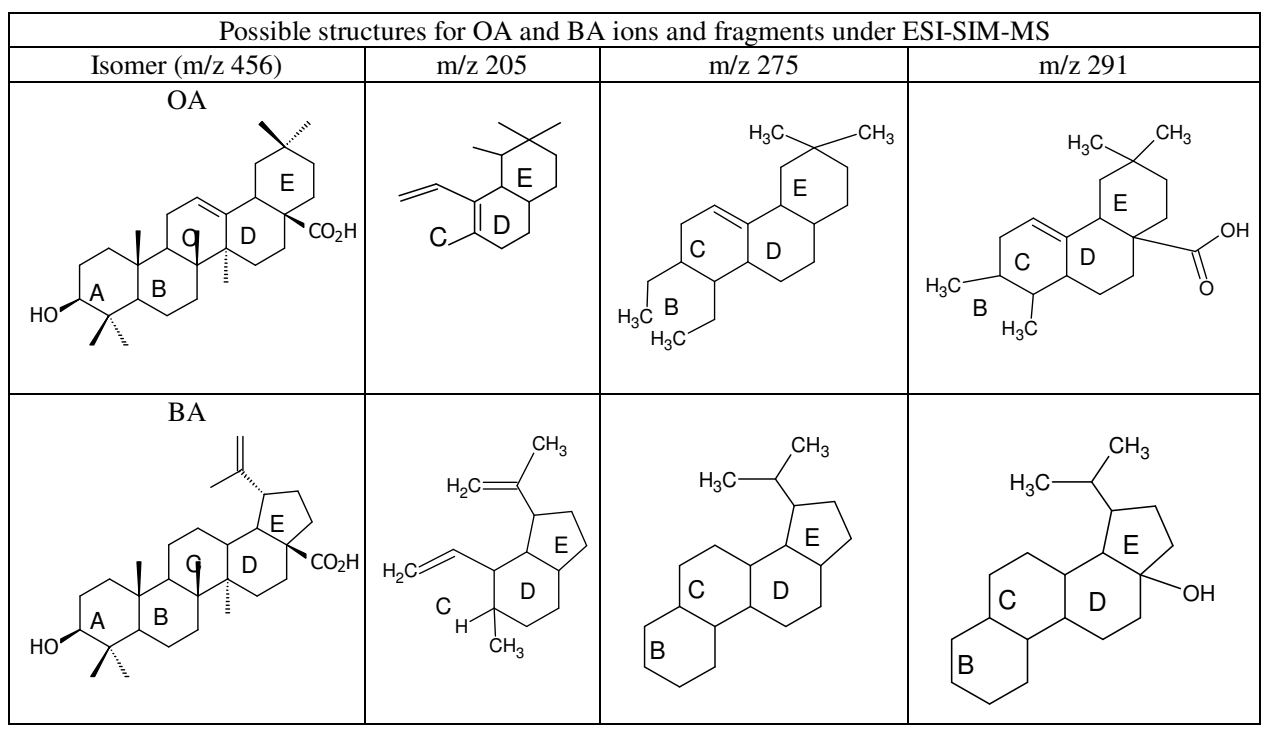

Measurements of $K_{D}$ and $\log P$ values for $O A$ and $B A$

The distribution coefficient $\left(\mathrm{K}_{\mathrm{D}}\right)$ for the isomers (BA and $\mathrm{OA}$ ) in the aqueous samples across the hydrophobic organic solvent made up of di-n-hexyl ether to the aqueous solution inside the lumen of the hollow fibre was calculated as follows (equation 1)

$$
\mathrm{K}_{\mathrm{D}}=\frac{\begin{array}{c}
\text { Concentration of the isomer (OA or BA) in the } \\
\text { Concentration of the isomer (OA or BA) in the aqueous sample solution }
\end{array}}{\text { Conceous solution (inside the lumen of hollow fibre) }}
$$

The diffusive flux for each of the isomers (OA and BA) in the sample solution was worked out according to Fick's first law of diffusion. By using Fick's first law, the diffusive flux of components in a sample solution can be related to the concentration. According to this law the flux proceeds from regions of high concentration to regions of low concentration, with a magnitude that is proportional to the concentration gradient. Mathematically, Fick's law can be represented as follows:

$$
\text { Flux }(\mathrm{F}) \text { across the hollow fibre }=-\mathrm{D} \frac{\Delta \mathrm{C}}{\Delta \chi}
$$

where, $\mathrm{D}$ is the diffusion coefficient with units of length ${ }^{2}$ time $^{-1}$, while $\Delta \mathrm{C} / \Delta \chi$ refers to the concentration gradient with units of (concentration of isomer) length ${ }^{-2}$ time $^{-1}$. NB: $\chi$ denotes radius of the hollow fibre with units of [concentration of isomer (per unit volume) length ${ }^{-1}$ ]. 
Also, diffusion flux has units of $[$ (amount of isomer $) /($ area.time $)]=[($ amount of isomer).length ${ }^{-2} \cdot$.time $\left.^{-1}\right]$. Diffusion coefficient or diffusivity is expressed as [area/time] = [length ${ }^{2}$.time ${ }^{-1}$ ]. Gradient of C/gradient of $\mathrm{x}$ accounts for [concentration/length], which is equal to [(amount of isomer/volume $) /$ length $]=\left[(\right.$ amount of isomer $) \cdot$ length $\left.^{-4}\right]$.

The flux and concentration relationship is governed by the law of conservation of mass which states that the cumulative amount of solute crossing any medium $\mathrm{x}$ in a total amount of time, $t$ should be equal to the total amount of that substance at that medium $x$ at time $t(27)$.

$$
V \theta_{m} \int_{0}^{t} C_{F}\left(x, t^{\prime}\right) d t^{\prime}=\theta_{\text {tot }} \int_{s}^{\infty} C_{R, t o t}\left(x^{7}, t\right) d x^{\prime}
$$

where $C_{F}$ is the flux rate, $C_{\text {Rtot }}$ is the original concentration and $\theta_{\text {tot }}$ refers to total porosities.

Rearranging equation 3 , making $\mathrm{C}_{\mathrm{F}}$ subject we get the following.

$$
C_{F}(x, t)=\frac{1}{\theta_{W}} \int_{x}^{\infty} C_{R, t o t}\left(x^{\prime}, t\right) d x^{\prime}
$$

The amounts of the deprotonated ions for both isomers as observed in the MS results were calculated from the standard calibration curves which were prepared by injecting increasing concentrations of standards of both OA and BA. The intensities for each concentration were recorded and plotted against the corresponding concentrations to get the linear calibration curves. The average $\mathrm{K}_{\mathrm{D}}$ values obtained for BA and OA was 0.29 and 0.16 , respectively. The calibration curves for a deprotonated molecular ions of BA and $\mathrm{OA}(\mathrm{m} / \mathrm{z}=455)$ gave acceptable calibration curves with $r^{2}=0.9$. Extracts from HFSLM process were quantified using these calibration curves.

The concentrations of extracted OA and BA obtained from HFSLM process (Tables 2 for BA isomer, $\mathrm{m} / \mathrm{z}=455$ ) were used to calculate the flux across the hydrophobic liquid membrane which was made up of di-n-hexyl ether. The flux measurements obtained were used to determine the flux rate for the extractions which were performed at different enrichment times. These data made it possible to calculate both distribution coefficient $K_{D}$ (according to equation 1) as well as the $\log \mathrm{P}$ values for the two isomers. Figures $4 \mathrm{a}$ and $4 \mathrm{~b}$ show that the flux was increasing as enrichment time was increased.

The flux for BA seems to be almost twice as much as compared to that of OA for the same enrichment times. This means that BA has a higher rate of crossing the hydrophobic organic membrane than OA when each is extracted at its optimal conditions for the same amount of time. This may be attributed to the differences in their chemical structures. From the measurements of flux and the distribution coefficients, the graphs for the diffusive flux rate versus $K_{D}$ were plotted which gave the values for $\log \mathrm{P}$ of the two isomers (Figures $5 \mathrm{a}$ and $5 \mathrm{~b}$ ).

Table 2. BA concentrations $(\mathrm{m} / \mathrm{z}=455)$ used for the calculations of flux and flux rate.

\begin{tabular}{|c|c|c|c|c|c|}
\hline Time & $\begin{array}{c}\text { BA ion count, } \\
\mathrm{m} / \mathrm{z}=455\end{array}$ & $\begin{array}{c}\text { BA Concentration, } \\
\mathrm{mg} / \mathrm{L}\end{array}$ & $\begin{array}{c}\text { Flux rate, } \\
\mathrm{mg} / \mathrm{min}\end{array}$ & Initial concentration, $\mathrm{mg} / \mathrm{L}$ & $\mathrm{K}_{\mathrm{D}}$ \\
\hline 5 & 83 & 7.699083 & 1.539817 & 100 & 0.076991 \\
\hline 30 & 167 & 12.73536 & 0.424512 & 100 & 0.127354 \\
\hline 60 & 216 & 15.67318 & 0.26122 & 100 & 0.156732 \\
\hline 90 & 322 & 22.02848 & 0.244761 & 100 & 0.220285 \\
\hline
\end{tabular}




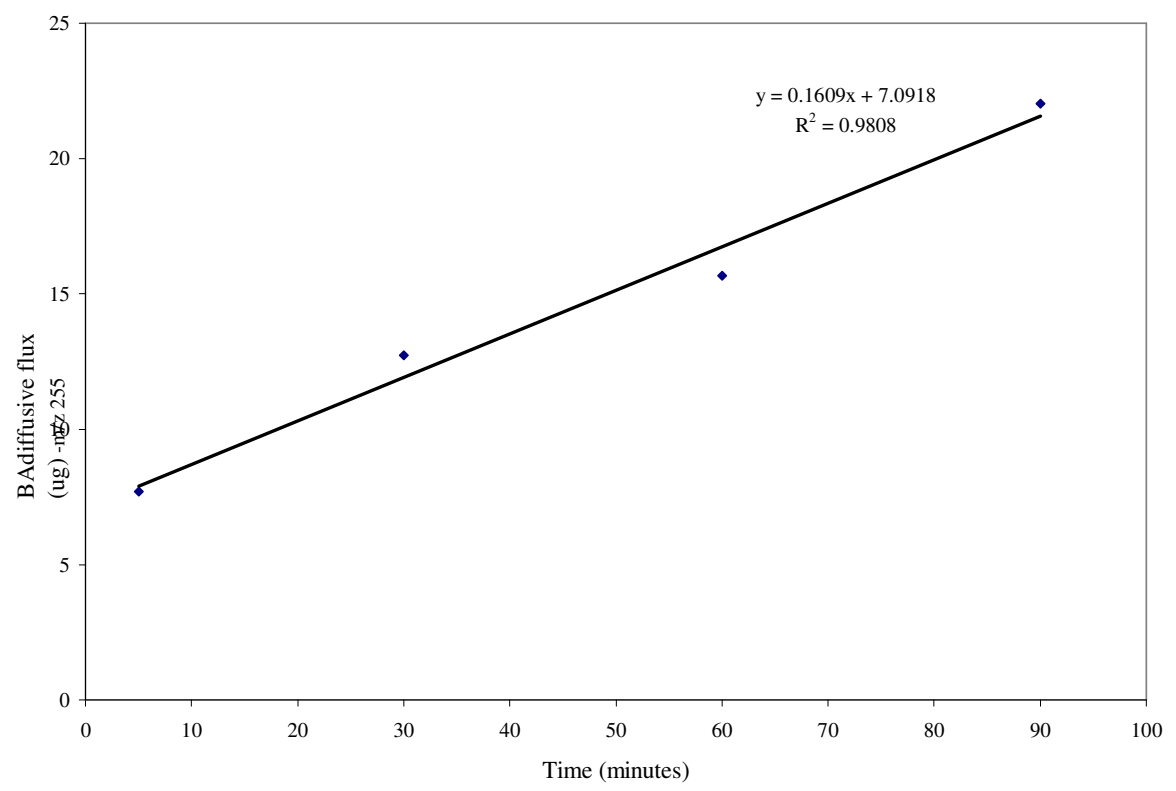

Figure 4a. Diffusive flux for BA $(\mathrm{m} / \mathrm{z}=455)$ at different enrichment times.

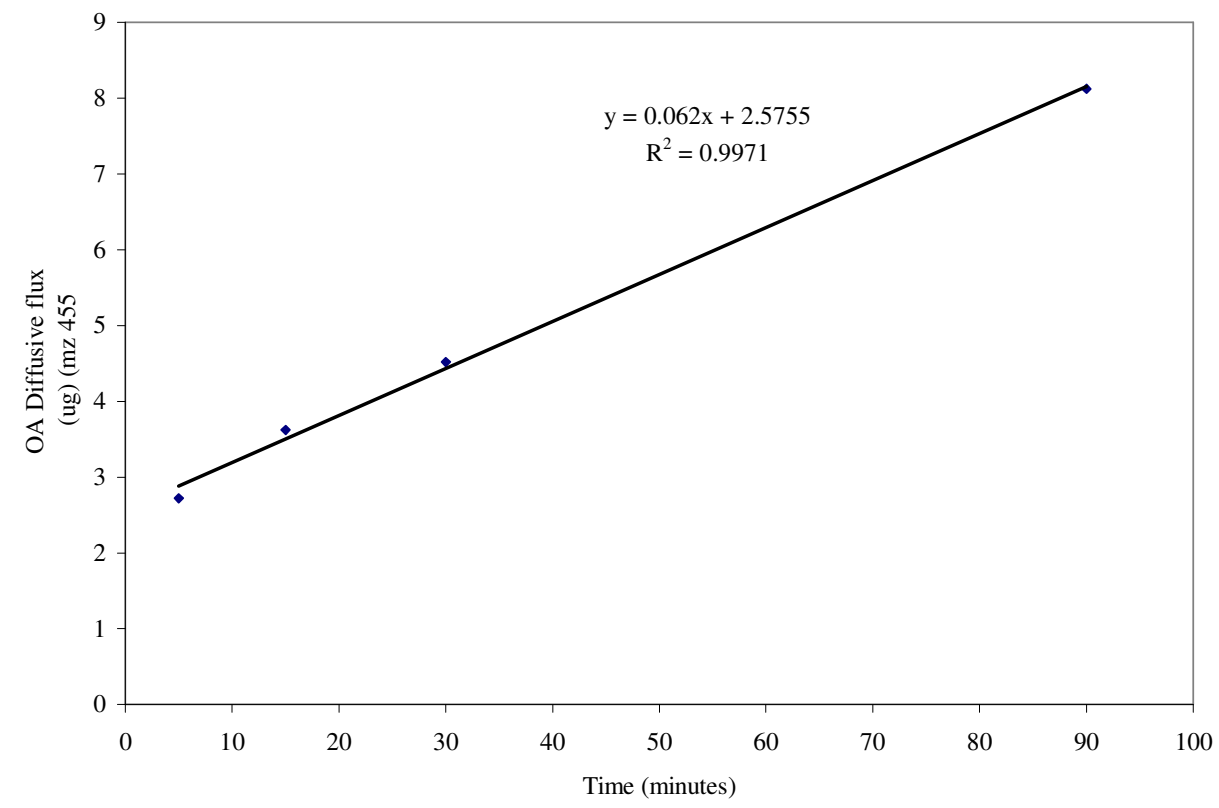

Figure $4 \mathrm{~b}$. Diffusive flux for $\mathrm{OA}(\mathrm{m} / \mathrm{z}=455)$ at different enrichment times. 


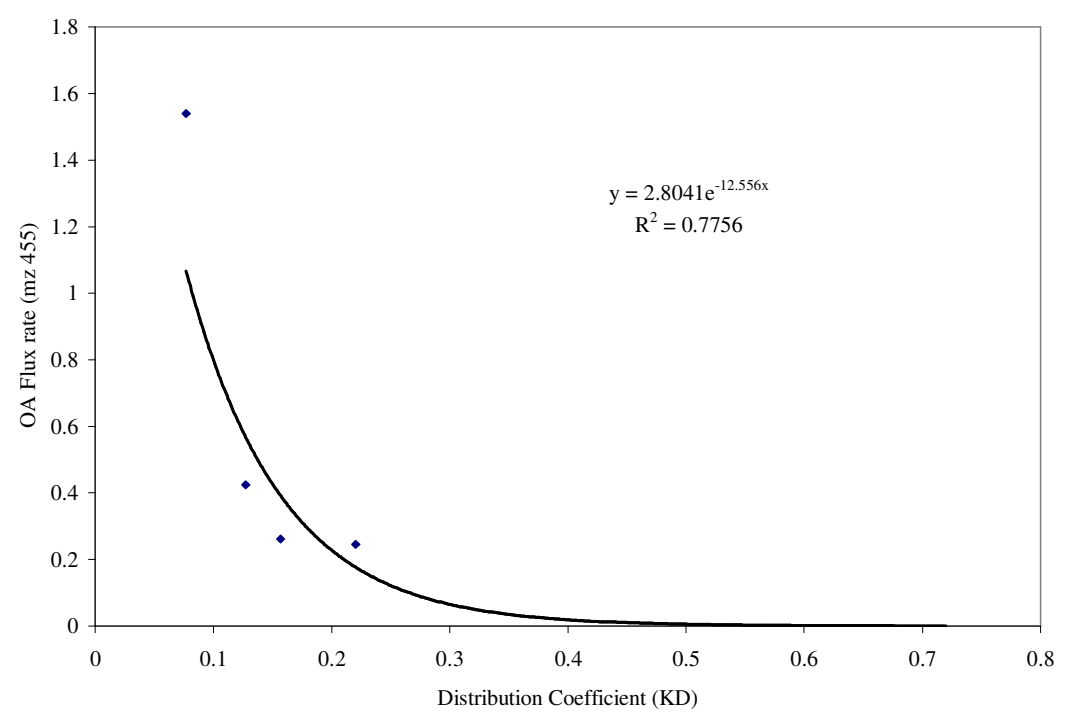

Figure 5a. OA diffusive Flux rate $\mathrm{Vs} \mathrm{K}_{\mathrm{D}}(\mathrm{m} / \mathrm{z}=455)$.

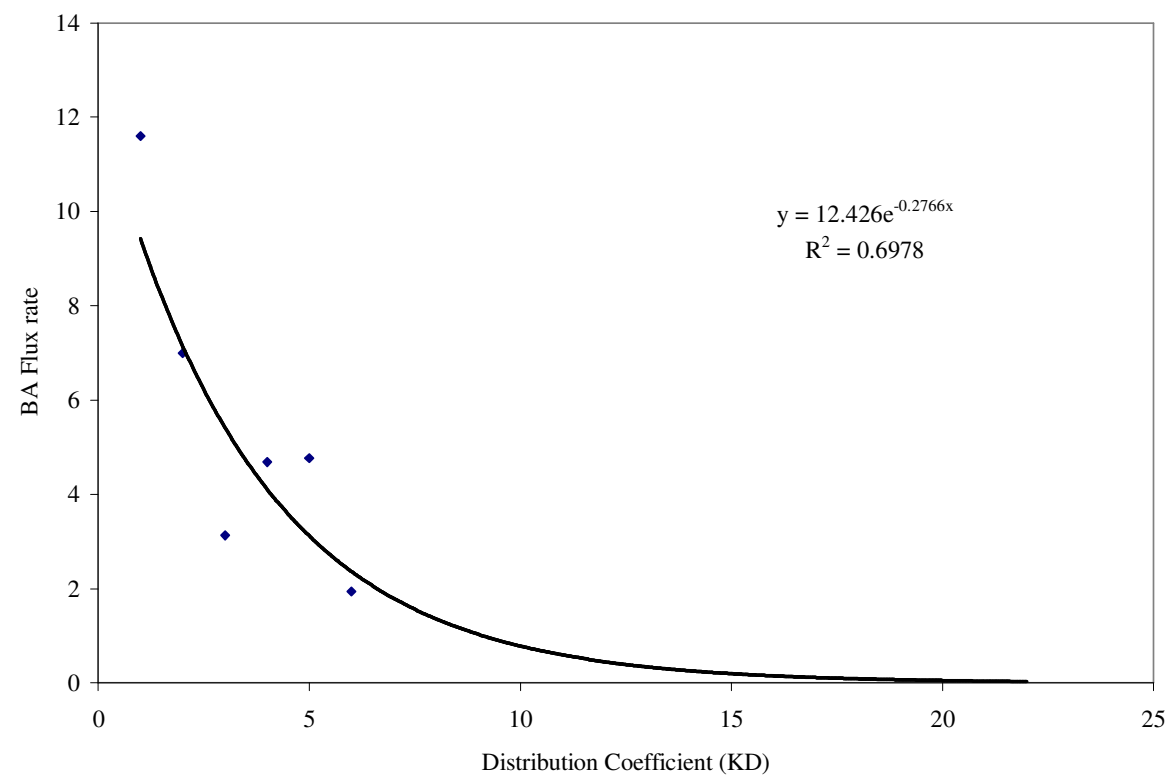

Figure 5b. BA Diffusive flux rate $\mathrm{Vs}_{\mathrm{D}}(\mathrm{m} / \mathrm{z}=455) \mathrm{BA}$.

From the exponential equations obtained from the curves, it was then possible to calculate the $\log \mathrm{P}$ values for both $\mathrm{OA}$ and $\mathrm{BA}$. The results showed that BA was slightly more hydrophobic than OA as the data for $\log \mathrm{P}$ showed that BA had 6.61 while OA had $\log \mathrm{P}$ value of 6.1. The obtained data were compared to the data reported in the literature using other techniques. The literature has $\log \mathrm{P}$ values for $\mathrm{BA}$ as 6.85 and 6.32 for OA [25]; other 
researchers have reported values ranging from 1.24 to 6.72 for OA [26]. Generally, comparisons for the $\log \mathrm{P}$ values obtained from this work are slightly lower than those reported by Claude and co-workers, and this may be due to the differences in the experimental conditions and set up. Table 3 summarizes the comparison for the $\log \mathrm{P}$ values for OA and BA.

Table 3. Comparison of $\log \mathrm{P}$ values obtained from this work and literature values.

\begin{tabular}{|c|c|c|}
\hline Isomer & $\begin{array}{c}\log \mathrm{P} \\
\text { (This work) }\end{array}$ & $\begin{array}{c}\log \mathrm{P} \\
\text { (Literature) }\end{array}$ \\
\hline $\begin{array}{c}\mathrm{BA} \\
\mathrm{pK}_{\mathrm{a}} 5.50\end{array}$ & 6.61 & $6.85[25]$ \\
\hline $\begin{array}{c}\mathrm{OA} \\
\mathrm{pK}_{\mathrm{a}} 5.11\end{array}$ & 6.12 & $\begin{array}{c}6.72[25] \\
6.46-7.47[26]\end{array}$ \\
\hline
\end{tabular}

\section{CONCLUSIONS}

HFSLM has been successfully used for the extraction, separation and for the measurements of $\mathrm{K}_{\mathrm{D}}$ and $\log \mathrm{P}$ values for BA and OA. A comparison with other techniques show that there is a close similarity between the values obtained using other techniques and this affirms the strength of the method developed in this study.

\section{ACKNOWLEDGEMENTS}

CAE expresses her profound appreciation to the Research Office of UKZN for post-doctoral fellowship and Mr. Yakubu of the Herbarium section, Faculty of Pharmacy, OAU, Ile Ife for identification and collection of Tectonia grandis.

\section{REFERENCES}

1. Yogeeswari, P.; D. Sriram D. Curr. Med. Chem. 2005, 12, 657.

2. Kashiwada, Y.; Wang, H.K.; Nagao, T.; Kitanaka, S.; Yasuda, I.; Fujioka, T.; Yamagishi, T.; Cosentino, L.M.; Kozuka, M.; Okabe, H.; Ikeshiro, Y.; Hu, C.Q.; Yeh, E.; Lee, K.H. J. Nat. Prod. 1998, 61, 1090.

3. Rabi, T.; Shukla, S.; Gupta, S. Mol. Carcinogenesis 2008, 47, 964.

4. Mullauer, F.B.; Kessler, J.H.; Medema, J.P. Apoptosis 2009, 14, 191.

5. Wang, L.; Li, Z.L.; Song, D.D.; Sun, L.; Pei, Y.H.; Jing, Y.K.; Hua, H.M. Planta Medica 2008, 74, 1735.

6. Drag, M.; Surowiak, P.; Drag-Zalesinska, M.; Dietel, M.; Lage, H.; Oleksyszyn, J. Molecules 2009, 14, 1639.

7. Fulda, S. Mol. Nutr. Food Res. 2009, 140, 53.

8. Subramanyam, R.; Gollapudi, A.; Bonigala, P.; Chinnaboina, M.; Amooru, D.G.J. Photochem. Photobiol. B: Biol. 2009, 94, 8.

9. Goff, R.D.; Thorson, J. S. Org. Lett. 2009, 11, 461.

10. Overton, E. Z. Physikal. Chem. 1897, 22, 189.

11. Meyer, H. Archiv Fuer Experimentelle Pathologie und Pharmakologie (NaunynSchiedebergis) 1899, 42, 10.

12. Baum, A. Naunyn-Schmiedebergs. Arch. Exp. Pathol. Pharmakol. 1899, 42, 119.

13. Fujita, T.; Iwasa, J.; Hansch, C. J. Am. Chem. Soc. 1964, 86, 5175.

14. Takács-Novák, K.; Avdeel, A. J. Pharm. Biomed. Anal. 1996, 14, 1405.

15. Kumar, K.; Sastre, A.M. Ind. Eng. Chem. Res. 2000, 39, 146. 
16. Msagati, T.; Chimuka, L.; Cukrowska, E. Water (SA) 2008, 34, 421.

17. Msagati, T.A.M.; Chimuka, L.; Cukrowska, E.; Tutu, H.; Majors, R.E. LCGC North America 2009, 27, 100.

18. Romero-González, R.; Pastor-Montoro, E.; Martínez-Vidal, J.L. Rapid Commun. Mass Spectrom. 2006, 20, 2701.

19. Berhanu, T.; Liu, J-F.; Romero, R.; Megersa, N.; Jönsson, J. Å. J. Chromatogr. A 2006, $1103,1$.

20. Garrido-Frenich, A.; Fontàs, C.; Salvadó V.; Hidalgo, M. J. Membr. Sci. 2003, 223, 39.

21. Mahato, S.B.; Kundu, A.P. Phytochemistry 1994, 37, 1517.

22. Perrin, D.D.; Dempsey, B. Buffers for $\mathrm{pH}$ and Metal Ion Control, Chapman and Hall: London; 1973, p 139.

23. Buchholz, K.D.; Pawliszyn, J. Environ. Sci. Technol. 1993, 27, 2844.

24. Norberg, J.; Tiruye, D.; Mathiasson, L.; Jönsson, J.Å. J. Sep. Sci. 2002, 25, 351.

25. Claude, B.; Morin, P.; Lafosse, M.; Andre, P. J. Chromatogr. A. 2004, 1049, 37.

26. Sánchez, M.; Theoduloz, C.; Schmeda-Hirschmann, G.; Razmilie, I.; Yañez, T.; Rodriguez, J.A. Life Sci. 2006, 79, 1349.

27. Zhang, Y.; Boris Baeumer, B.; David A. Benson, D.A. Geophys. Res. Lett. 2006, 33, 1. 